ECOLOGICA, Vol. 28, No 101 (2021), 125-133

https://doi.org/10.18485/ecologica.2021.28.101.19

Originalni naučni rad

UDC:551.583:004.738.5

\title{
Kompleksna uzajamna povezanost sajber prostora i klimatskih promena
}

\section{Complex interconnection of cyber space and climate change}

\author{
Marko Pavićević ${ }^{1}$, Maja Kljajić \\ 1,2Univerzitet Singidunum, Beograd, Srbija \\ 1,2Singidunum University, Belgrade, Serbia \\ Rad primljen: 17.01.2021, Rad prihvaćen: 26.02.2021.
}

Sažetak: Cilj ovog rada je analiza povezanosti klimatskih promena i sajber prostora, odnosno zaključak na koji jedan utiče na drugi. Cilj je ukazati koliko je važno kreirati sajber režim koji će biti uređen i putem kojeg će države na međunarodnom nivou moći da se nose sa izazovima klimatskih promena. Problem je u tome što je i za klimatske promene i za sajber prostor, jako teško utvrditi ko je odgovoran i ko narušava životnu sredinu i ko zloupotrebljava digitalnu infrastrukturu. Sa druge strane, vidi se sve veća povezanost, odnosno sve veća potreba da se protiv klimatskih promena bori uz pomoć sajber prostora. Klimatske promene nam ukazuju na to koliko je neophodna zajednička borba na međunarodnom nivou. Takva borba je nemoguća, ukoliko nemamo sajber režim, odnosno uređenu i regulisanu povezanost između država u polju sajber prostora.

Ključne reči: sajber prostor, klimatske promene, životna sredina, digitalizacija, COVID-19.

\begin{abstract}
The aim of this paper is to analyze the connection between climate change and cyberspace, ie the conclusion that one affects the other. The goal is to point out how important it is to create a cyber regime that will be regulated and through which countries will be able to cope with the challenges of climate change at the international level. The problem is that for both climate change and cyberspace, it is very difficult to determine who is responsible and who is disrupting the environment and who is abusing the digital infrastructure. On the other hand, there is a growing connection, ie a growing need to fight climate change with the help of cyberspace. Climate change shows us how necessary a joint struggle is at the international level. Such a struggle is impossible, if we do not have a cyber regime, that is, an orderly and regulated connection between countries in the field of cyberspace.
\end{abstract}

Keywords: cyber space, climate change, digitalization, COVID-19.

1orcid.org/0000-0002-9567-6198, e-mail: mpavicevic1989@gmail.com

²orcid.org/0000-0002-2232-5725, e-mail: mkljajic@singidunum.ac.rs 


\section{UVOD / INTRODUCTION}

Trend klimatskih promena, odnosno globalnog zagrevanja koji, potencijalno, može da ima posledice po životnu sredinu, čovečanstvo u celini i život svih na Zemlji, datira iz 19 veka, kada je Švedski hemičar Savante Arhenius otkrio da ljudi mogu da kreiraju efekat staklene bašte prilikom stvaranja ugljen dioksida. Globalno zagrevanje je koncept koji ukazuje na to da se prosečna temperatura zemljine atmosfere povećava kao rezultat ljudskih aktivnosti, kao na primer, sagorevanje fosilnih goriva i krčenje šuma. Tačnije, prilikom korišćenja nafte, uglja i prirodnog gasa, proizvodi se ugljen dioksid. Velika količina ugljen dioksida povećava temperaturu zemlje, istovremeno, aktivna deforestacija (krčenje šuma), ima za posledicu globalno zagrevanje i uništavanje životne sredine. Temperatura zemlje se menja, takođe, sama po sebi, na osnovu prirodnih tendencija, kao što su, vulkani, sunčevo zračenje i slično. Emisija gasova sa efektom staklene bašte u atmosferi, uravnotežuje se gasovima staklene bašte koji se prirodno apsorbuju. Na ovaj način, imali smo doslednu klimu koja kreira pogodno tlo za razvitak ljudske civilizacije. Države, svojim delanjem, kao što je, na primer, korišćenjem i paljenjem uglja, povećavaju količinu ugljen dioksida u atmosferi, i na taj način ubrzavaju proces destabilizacije klime. Posledice mogu biti vulkanske erupcije, podizanje nivoa mora, poplave i suše, lakše širenje epidemija i virusa, promena ekosistema i slično. Ukoliko dođe do zagrevanja Zemljine atmosfere, doći će i do velikih promena u oblasti životne sredite koje će imati drastičan uticaj ne ekosistem i razvitak ljudske civilizacije (Weart, 2008).

Digitalna revolucija kreira nove aktere i nove metode uticaja na međunarodna dešavanja. Akteri u polju sajber bezbednosti, imaju prirodu anonimnosti i efektivne protivmere su, u mnogim slučajevima, izazovne i teško izvodljive. Sajber prostor predstavlja novo polje sukoba koje će uticati na države i njihovo stanovništvo (Cilluffo, Cardash, 2013). Sajber prostor je koncept koji opisuje međusobno povezanu i široko upotrebljivu digitalnu tehnologiju. Termin koriste države, lideri kompanija, preduzetnici i tehnološki eksperti za opis globalno-tehnološkog okruženja koje ima tendencije kreiranja globalne mreže i međusobno zavisne informacione infrastrukture. Internet je ljudskoj zajednici olakšao život i napravio svet manjim, ali je kreirao aktere koji koriste njegove prednosti sa ciljem "hakovanja" relevantnih resursa. Sajber bezbednost uključuje domen bezbednosti u polju informacionih sistema koje ima za cilj da sačuva poverljivost $\mathrm{i}$ integritet informacija (Seemma et al, 2018). Pretnja u polju sajber bezbednosti predstavlja smišljenu akciju koja ima za cilj da ošteti kompjuterski sistem. Ona može biti namerna, prouzrokovana aktivnošću čoveka ili ne namerna koja je rezultat sistemske greške i prirodna katastrofa kao posledica prirodne nepogode. Najveća pretnja je po obaveštajne informacije koje mogu da naprave dugotrajnu štetu po države. Na primer, napad na informacionu infrastrukturu koja kontroliše avio saobraćaj može da prouzrokuje ljudske žrtve. Sajber pretnja može da proistekne iz država koje su neprijateljski orijentisane jedna prema drugoj i koje imaju za cilj da dođu do relevantnih obaveštajnih informacija. $U$ istoj meri, pretnja dolazi iz terorističkih grupa koje imaju manje kapacitete, ali koje, takođe, mogu da nanesu štetu državama i pojedincima. Postoje hakeri unutar korporacija, čiji je cilj krađa intelektualne svojine drugih korporacija, ili nanošenje štete državama i njihovim kompjuterskim infrastrukturama. Osim toga, sajber pretnje mogu da budu rezultat delovanja na ličnoj osnovi, slučajne aktivnosti ovlašćenih korisnika sajber prostora i slično (Slavković, Kršljanin, 2015; Gnjatović, 2018).

Sajber pretnje predstavljaju veliki rizik za države, korporacije i individue. Potrebna je kontrola i kolaboracija između različitih strana o tome kako, na najbolji način, zaštiti infrastrukturu od neželjenih napada. Klimatske promene, odnosno globalno zagrevanje i sajber bezbednost predstavljaju najurgentnije probleme dvadeset i prvog veka. Sajber prostor ima potencijal da utiče na klimatske promene na pozitivan i negativan način. Na primer, države, ukoliko vode sajber rat između sebe, neće iskoristiti svoj kapacitet da reše probleme globalnog zagrevanja i klimatskih promena. Paradoksalno, klimatske promene mogu da utiču na države i različite aktere da usaglase svoje sajber strategije.

Trenutno je ceo svet pogođen pandemijom izazvanom virusom COVID-19. Na svetskom nivou, pandemija je proglašena 11. marta 2020. godine od strane Svetske zdravstvene organizacije (World Health Organization, 2019). Posledice izazvane širenjem virusa još uvek nisu vidljive, ali je definitivno da će pomeriti granice dosadašnjeg načina života. $U$ izveštaju Ujedinjenih nacija (Razvojni program) navodi se da je pandemija COVID-19 sistemska kriza ljudskog razvoja (Program Ujedinjenih nacija za razvoj, 2020). Nastala je kao rezultat neadekvatne interakcije pojedinca sa prirodom i njenim ekosistemom, uključujući naglašene nejednakosti među ljudima i neravnomerne ekonomske aktivnosti. Istovremeno, situacija sa virusom nam je pokazala koliko je digitalizacija svega što nas okružuje važna i neophodna (Vassileva i dr, 2020). Odnosno, pokazuje nam koliko je savremeni život nezamisliv bez tehnologije, a samim tim koliko će sajber prostor 
imati uticaj na naš svakodnevni život (Ujedinjene Nacije Srbija, 2020), (Radić i dr, 2020).

\section{MATERIJALI I METODE / MATERIALS AND METHODS}

\section{Sajber prostor / Cyber space}

Povezanost sajber prostora i fizičkog prostora je velika i sajber prostor će u sve većoj meri uticati na fizički prostor s obzirom na svoju veštačku i kreativnu prirodu ekspanzije. Sajber prostor može da služi kao protekcija fizičkom prostoru, a može i da bude faktor nestabilnosti koja narušava fizički prostor. Fizički prostor predstavlja prirodni kosmos koji uključuje kopno, more, vazduh i svemir. Sajber prostor predstavlja ljudsku kreaciju koja uključuje informacione sisteme i koja će imati sveobuhvatni uticaj na fizički prostor. Sajber prostor za razliku od fizičkog prostora, nema fizička ograničenja, odnosno njegov potencijal za razvijanje je neograničen (Vuletić, 2017). Međunarodni odnosi su polje istraživanja putem kojeg se analiziraju sajber konflikti i posledice izazvane ovim konfliktima. Pitanje koje se postavlja je koliko sajber konflikt može negativno uticati na međunarodne odnose? Na ovo pitanje je jako teško odgovoriti jer, i dalje, nauka i politika nemaju konsenzus o tome šta je tačno sajber bezbednost i na koji način utiče na države, sve njene aktere i njihove odnose. Sajber namera se fokusira na eksternu pretnju koja ima za cilj da, kroz digitalne kanale, prodre $u$ informacione sisteme država i naprave štetu (Maness, Valeriano, 2015). Ne postoji, i dalje, konsenzus o tome šta je tačno sajber napad. Jedan od načina, putem kojeg možemo da argumentujemo da je sajber napad počinjen je ukoliko postoji šteta koja je izazvana tim napadom. Takođe, nije dovoljno da je šteta napravljena, već i kolika je ta šteta, odnosno koliko utiče na informacioni sistem država i njenih aktera. Ozbiljnost istrage od strane država, kompanija ili privatnih aktera zavisi od toga kolika je šteta napravljena. Ukoliko šteta nije velika, postoji šansa da će istraga biti ograničena, a u nekim slučajevima i prekinuta a samim tim, to ima za posledicu da li se, stvarno, desio sajber napad, koje su njegove posledice i ko su akteri iza tih napada (Rid, Buchanan, 2014).

Jedna od relevantnih sajber pretnji je sajber špijunaža, čiji je cilj krađa relevantnih informacija koje mogu da se zloupotrebe. Države koriste sajber špijunažu kako bi došle do relevantnih informacija koje mogu da pripomognu ekonomskoj i vojnoj modernizaciji (Gilli, Gilli, 2019; Nešković, 2011). Za razliku od tradicionalnih napada uz pomoć konvencionalnog oružja koje poseduje država, u sajber napadu mogu da učestvuju nedržavni akteri koji mogu da sakriju svoj identitet. Države, takođe, mogu da sakriju svoj identitet prilikom sajber špijunaže i da okrive nedržavne aktere. Samim tim, sajber pretnja je mnogo veća zbog svoje prirode tajnosti. Na ovu pretnju se nadovezuje i sajber terorizam koji predstavlja paradigmu budućih ratova. U sajber ratu, države i nedržavni akteri mogu da iskoriste tehnologije informacionog ratovanja kako bi sledili svoje ciljeve (Rathmell, 2008). Korišćenje Interneta za sprovođenje radnji koje mogu prouzrokovati gubitak života, fizičke povrede, a čiji cilj je ostvarivanje ideoloških i političkih agendi putem intimidacije. Sajber terorizam je Internet pretnja u kojoj jedna strana pokušava, putem kompjuterskih mreža, da postigne svoj cilj narušavanja bezbednosti druge strane.

Problem sajber pretnje je nevidljivost neprijatelja, čija je identifikacija, u mnogim slučajevima, nemoguća, a samim tim i kreiranje mehanizama za njegovu buduću prevenciju delovanja. Prve sajber pretnje osamdesetih godina prošlog veka su se ispoljavale kroz sajber špijunažu i eksploataciju kompjuterskih (državnih) mreža. Kasnije, devedesetih godina prošlog veka, sumnja se na nedržavne aktere koji su pretnja civilnoj infrastrukturi. Početkom dvadeset i prvog veka, državni akteri koji su opet predmet zabrinutosti, se vode kao teroristi koji koriste sajber kapacitete da slede svoje ciljeve (Jonev, 2016). Države sve više, uviđajući da sajber domen predstavlja sve veću pretnju, analiziraju ovo područje zabrinutost (Lawson, 2013). Dvadeset i prvi vek će biti okarakterisan kao kompleksna međuzavisnost u kojoj su državni i nedržavni akteri uključeni u sajber prostor i koriste njegove kapacitete da slede svoje ciljeve. Sajber moć se zasniva na korišćenju elektronskih i računarskih informacija i predstavlja sposobnost jedne strane da uspešno, u svoje svrhe, koristi elektronsko i međusobno povezane izvore informacija. Neograničena moć sajber prostora leži u tome da jedna strana utiče na drugu stranu i na ishode u sajber prostoru, ili pak, može koristiti sajber instrumente da sledi svoje ciljeve u domenima van sajber prostora (Nye, 2010). Sajber prostor, na primer, može da se koristi sa ciljem da jedna država ukrade intelektualnu svojinu kompanija druge države, a može da koristi i u svrhe da ošteti informacioni sistem koji drži pod kontrolu berzu (Miladinović-Bogavac, 2017). Sajber prostor ima veliki kapacitet sa povećanjem svog domena u polju međunarodnih odnosa i dešavanja. Nedržavni akteri i male države, sa svojim sajber kapacitetima, imaju mogućnosti da naprave veliku štetu. Sajber prostor kreira difuziju moći na međunarodnom nivou i novo globalno okruženje u kojoj će postojati puno aktera koji mogu da utiču na svakodnevni život ljudi. 


\section{Klimatske promene / Climate change}

Ljudske aktivnosti od 1970. godine su uzrok sve veće koncentracije ugljen-dioksida, metana i azot-oksida u atmosferi. Ova koncentracija je u značajno meri veća nego ona pre industrijske revolucije. Upotreba fosilnih goriva je dovela do veće koncentracije ugljen-dioksida, a aktivnost unutar privrede i poljoprivrede do koncentracije metana $\mathrm{i}$ azot-oksida. Najveći efekat staklene bašte prouzrokuje ugljen dioksid (Change, 2007). Efekat staklene bašte je pre ljudske aktivnosti imao svoj prirodni tok koji je dovodio do prirodnog i ne preteranog zagrevanja zemljine površine i njenih elemenata, a nakon njega, doveo je do globalnog zagrevanja i klimatskih promena koje mogu imati negativ uticaj (Belić, 2006). Pokazatelji koji ukazuju na globalno zagrevanje i klimatske promene su povećanje temperature na površini zemlje, podizanje nivoa mora i povećanje temperature podzemnih slojeva zemlje. Temperatura zemljine površine u poslednjih sto godina je porasla, u proseku, jedan stepen celzijusa, a od 1975. godine postoji ubrzan rast. Istovremeno, zagrevanje zemljine površine dovodi do povećanja nivoa mora, kao rezultat topljenja polarnog leda i glečera. $U$ poslednjih nekoliko decenija, nivo mora, raste godišnje u proseku oko 3,4 milimetara, a u poslednjih sto godina, nivo mora je porastao oko osamnaest centimetara. Treći pokazatelj, manje relevantan s obzirom na manjak postojanja sveobuhvatnih analiza je povećanje temperature podzemne vode. Bušotine, tuneli $i$ rudnici ukazuju na to da podzemna temperatura koje generišu stene raste (Aizebeokhai , 2009). Klimatske promene mogu da imaju veliki uticaj na ekološki sistem koji može da dovede do velikih promena u oblasti životne sredine, odnosno veliki uticaj na zdravlje ljudi (Blagojević, 2009). Ove promene mogu primete putem ekstremnih vremenskih prilika, požare, oštećenje ozonskog omotača, lakše širenja zaraznih bolesti i poremećaj sistema proizvodnje hrane. Sve ove promene mogu da dovedu do velike panike unutar država i do velikog broja smrtnih slučajeva na globalnom nivou.

Globalno zagrevanje predstavlja prosečno uvećanje temperature zemljine površine koje može prouzrokovati modifikacije klimatskih okolnosti. Može biti posledica emisije gasova staklene bašte koje mogu biti rezultat prirodnog ili ljudskog delovanja. Klimatske promene su formulisane kao bilo kakve drastične promene u klimatskim merama (temperatura, padavine, vetar) i koje traju duži vremenski period (Ngongeh et al, 2014). Uzroci klimatskih promena mogu biti prirodni koji uključuju menjanje intenziteta sunca, promena cirkulacije okeana i slično. Istovremeno, mogu biti ljudske prirode i oni uključuju sagorevanje fosilnih goriva i deforestaciju. Ljudsko delovanje ima najveći uticaj na globalno zagrevanje koje dovodi do klimatskih promena koje već u sadašnjosti ima posledice, a tek će prouzrokovati probleme u budućnosti. Jedna od vidnih promena je otopljavanje leda širom sveta na Zemljinim površinama, odnosno topljenje planinskih glečera i ledenih pokrivača na Antarktiku i Grenlandu. Otopljavanje leda dovodi do povećanja nivoa mora na Zemljinoj površini. Ovakva pojava dovodi do toga da određene životinjske vrste nestaju, a da neke moraju da migriraju u potrazi za hladnijim krajevima. Takođe, klimatske promene dovode povećanja kiša i snežnih padavina u određenim regijama, dok u drugim postoje velike suše koje dovode do požara, uništenih ratarskih kultura i nestašice vode. Budućnost predviđa da će klimatske promene, prvenstveno, dovesti do podizanje nivoa mora, uragana i oluja koji će biti sve snažniji, poplave i suše će postati sve učestalije i intenzivnije, postojaće manja raspoloživost slatke vode, snažnije širenje virusa i celokupna promena ekosistema (National Geographic, 2020). Efekat staklene bašte je imao prirodan ciklus u prošlosti koji je narušen delovanjem čoveka i koji će kasnije, paradoksalno, imati efekat na život tog istog čoveka koji je uzrok ekološkog disbalansa i narušavanje prirodnog ciklusa ekosistema.

Poricanje postojanja klimatskih promena je veliki problem današnjice $u$ kojem se ljudi vode subjektivnim osećajima i ličnim vrednostima, umesto činjenicama. U ovome postoje dva problema: jedan je neznanje, a drugo je poricanje. Ukoliko ljudi nemaju znanja o određenoj temu, imaće mehanizam odbrane koji će dovoditi do toga da se ignorišu činjenice. Poricanje se, takođe, ogleda u tome da ljudi odbijaju realnost jer ona deluje jako pesimistično. Istovremeno, politika ima veliku ulogu u edukaciji populacije o tome koliko i na koji način klimatske promene mogu u budućnosti uticati na živote ljude. Time, ukoliko ljudi ne iskuse klimatske promene ili ne vide opipljiv dokaz, velika je verovatnoća da će poricati naučne činjenice i da neće verovati političarima. Pozitivan korak ka zajedničkoj saradnji i širenju svesti o tome koliko je važna zajednička borba o klimatskim promenama je Pariski sporazum koji je potpisan 2015. godine u Parizu. Zadatak ovog sporazuma je da zaustavi povećanje globalne temperature, odnosno da očuva prosek globalne temperature ispod 2 stepena celzijusa. Takođe, kooperacija između različitih država, pomoć ekonomsko slabijim državama sa ciljem kreiranja "eco-friendly" globalnog okruženja. Zemlje u razvoju, pogotovo, insistiraju na tome da cilj bude održanje temperature do 1,5 stepeni 
celzijusa. Postoji šansa da će prekoračenje od 1,5 stepeni celzijusa najviše uticati na zemlje u razvoju. Ukoliko se ne postigne cilj od 1,5 stepeni celzijusa, populacije i ekosistemi u tropskim delovima sveta, koji nemaju u velikom broju slučajeva razvijenu ekonomiju će biti narušeni (King, Harrington, 2018). $\mathrm{S}$ obzirom na povezanost i globalizaciju, problem u jednom delu sveta uvek utiče na probleme u drugom delu sveta. Tačnije, problem u zemljama u razvoju koji je uzrok klimatskih promena, dovešće do problema i u razvijenim državama koje u prvi mah mogu da se nose sa posledicama klimatskih promena ali ne i u dužim periodima.

\section{Sajber prostor i klimatske promene / Cyber space and climate change}

Informacioni sistemi i digitalizacija sve više utiču na naše živote, odnosno njihova poverljivost $i$ integritet su od velike važnosti za funkcionisanje ljudskog roda. Svako narušavanje poverljivosti $\mathrm{i}$ dostupnosti informacija, ima veliki uticaj na uspešno funkcionisanje celokupnog društva. Države, kompanije i pojedinci, kontinuirano, kreiraju nove informacione sisteme, a klimatske promene mogu kreirati nove ranjivosti koje utiču na integritet $i$ poverljivost informacionih sistema. Sajber prostor i klimatske promene predstavljaju dva najvažnija faktora ljudske civilizacije dvadeset i prvog veka. Postoje mnoga poređenja između navedenih. Pre svega, sajber pretnje i klimatske promene su globalni faktori koji ne poznaju granice i koje utiču na svaku osobu na ovoj planeti. Svi mi zavisimo od toga kako će klimatske promene uticati na naš ekosistem, odnosno na naš život, dok, u sve većoj meri, na ljude utiče digitalizacija svih relevantnih informacija. Takođe, preveliko korišćenje prirodnih resursa je dovelo do iscrpljena, a preveliko korišćenje Interneta je dovelo do kriminalnih (sajber) aktivnosti. Identifikacija onih koji narušavaju i zloupotrebljavaju sajber prostori i životnu sredinu je jako teška. Postoji trend svesti o tome da je važno sprečiti dalje narušavanje životne sredine, kao što je, jako važno, regulisati sajber prostor koji, sve više, postaje meta narušavanja poverljivosti i integriteta informacija. Još jedan zajednički faktor, koji dele sajber prostor i klimatske promene, su zastarelost mehanizama po kojima treba rešavati probleme (Dqindia, 2020). Ovakva povezanost dovodi do argumenta da je neophodno posmatrati ova dva segmenta kao jednu celinu zarad rešavanje svih budućih izazova i problema. Život i funkcionisanje čovečanstva u celini, u velikoj meri, zavisi od klimatskih promena i sajber prostora, da bi se ova dva segmenta uzimala u obzir posebno. Varijable koje utiču na ova dva segmenta su različiti, ali rizici koji proističu iz njih su antropogeni, a samim tim uzajamno povezeni (Allen, 2014). Drugim rečima, i sajber prostor i klimatske promene imaju zajednički ishod po ljudski rod. Na primer, paljene fosilnih goriva i hakerski napad na informacioni sistem zajedno mogu da utiču na kontrolu bezbednosti vode i hrane u državi. Sajber prostor ima mogućnost da uspori proces klimatskih promena, dok klimatske promene imaju potencijal da destabilizuju informacione sisteme kao rezultat sajber kriminala (Arntz, 2020). Drugih rečima, određene strane žele da iskoriste destabilizovanu globalnu ekološku krizu, kako bi hakovale sisteme i dalje narušile ekosistem. Potrebna je sinhronizacija ova dva segmenta, kako bi države rešile predstojeće izazove.

Problemi sajber prostora i klimatskih promena će uticati na više nivoa državnog sektora, državnih institucija, i privatnih aktera. Izazov je regulacija sajber prostora sa ciljem kreiranja pouzdane informacione infrastrukture koja će doprineti borbi protiv klimatskih promena. Sajber prostor ima, još uvek, nerazvijenu regulativu unutar država, a kompletno nerazvijenu na globalnom nivou. Borba protiv klimatskih promena dobila je zamah Pariskim dogovorom, nakon koje je počela jedna formalna $\mathrm{i}$ zajednička borba protiv klimatskih promena. Regulacija sajber prostora na globalnom nivou može da dovede do kreiranja globalne informacione infrastrukture i da služi sinhronizaciji borbe protiv klimatskih promena na globalnom nivou. Trend klimatskih promena je globalnog karaktera, a samim tim regulisanje sajber prostora na globalnom nivou može da dovede do lakše i sinhronizovane globalne borbe protiv klimatskih promena. Zajednička sajber infrastruktura može da dovede do većeg poverenja između država, do veće transparentnosti koja dovodi do efikasnije borbe protiv klimatskih promena. Drugim rečima, sajber prostor pruža tehničku podršku državama u daljoj borbi. Putem sajber prostora, postoji mogućnost kreiranja pravnog okvira koji bi olakšao koordinaciju inicijativa i uspostavljanje platformi za razmenu znanja (Carr, Lesniewska, 2020) koja bi omogućila lakšu i efikasniju borbu protiv klimatskih promena. Problem nastaje u tome da je svako kreiranje regulativnog okvira na međunarodno nivou jako teško, jer države teško prihvataju međunarodnu instituciju koja nameće svoju regulativu. Klimatske promene su globalni fenomen i zahteva globalnu inicijativu i globalno delovanje koje će dovesti do boljitka. Nesklad je u tome što države žele pomoć drugih država, a ne žele uplitanje u svoj suverenitet $i$ pravni okvir. Sajber prostor je novi segment koji nije, u velikoj meri, regulisan ni na državnom nivou, a daleko je od toga da pridobije pravne okvire na međunarodnom nivou. Posledice klimatskih prome- 
na će uticati na države da uvide moć sajber prostora, koji ima mogućnost efikasnog tehničkog delovanja na globalnom nivou, odnosno mogućnost koju sajber prostor pruža u segmentima borbe protiv klimatskih promena. Sinhronizacija globalnog delovanja u segmentu klimatskih promena zavisi od kreiranja pravnog okvira na globalnom nivou $u$ segmentu sajber prostora. Ova dva faktora su međusobno povezana, zavise jedan od drugog i svest država o njihovoj međusobnoj povezanost će dovesti do veće regulacije sajber prostora, a samim tim i do veće zajedničke borbe protiv klimatskih promena.

Veoma je izazovno napraviti vezu između sajber prostora i klimatskih promena. Klimatske promene su rezultat ljudskog delovanja na spoljnu atmosferu, a sajber prostor predstavlja jedan unutrašnji svet $i$ veštačku tvorevinu. Povezuje in činjenica da ih kreira čovek i da zajedno utiču na prirodna dobra, kao što su voda, vazduh i slično (N2 Concultants, 2015). U istoj meri ih povezuje činjenica da u svetu postoji kompletna digitalizacija informacija, a samim tim borba protiv klimatskih promena zahteva veće povezivanje sa sajber prostorom u cilju efikasnijeg odgovora na problem. $\mathrm{Na}$ primer, sajber napad na infrastrukturu neke operacije, recimo nuklearne elektrane, može da ima veliki uticaj, ne samo na kompjutersku infrastrukturu, nego i na ljudske živote. Takođe, sajber napad na infrastrukturu koja je povezana sa klimatskim promenama, takođe, može imati posledice po ljudske živote (Hossain, 2018). $\mathrm{Na}$ primer, sajber napad i gubitak podataka o rastu nivoa mora u nekim delovima sveta, može uticati na to da država ne pokrene, na vreme, akciju iseljavanja ljudi. $U$ novijoj istoriji, poverljivost digitalnih podataka je jako važno za ljudske živote. Najveća povezanost sajber prostora i klimatskih promena je upravo u tome da sajber prostor omogući poverljive podatke, kako bi borba protiv klimatskih promena bila uspešna. Ukoliko ljudi i zaposleni $u$ institucijama koji se bave klimatskim promenama, nemaju potpune i tačne podatke, neće biti u mogućnosti da se organizuju na pravi način i da vode borbu odgovarajućim sredstvima.

$\mathrm{U}$ poslednjih nekoliko godina, sajber prostor i klimatske promene postaju relevantni faktori u polju bezbednosti i ekonomije. Sajber prostor i klimatske promene, u sve većoj meri, predstavljaju problem za kompanije. Istovremeno, trend unilaterizma $u$ svetu dovodi do toga da je svaka sinhronizovana borba država u domenu sajber bezbednosti i klimatskih promena, veoma izazovna. $U$ isto vreme, klimatske promene širom sveta, utiču na živote ljudi i postoji sve više sajber napada, pre svega $u$ oblasti poslovanja. Problem $\mathrm{i}$ jednog $\mathrm{i}$ drugog domena je neregulisanost na globalnom nivou gde međunarodne institucije nemaju mehanizme za delovanje. Ne postoji globalna inicijativa koja će se suočiti, sinhronizovano, sa problemima sajber prostora i klimatskih promena (Saldinger, 2018). Države putem sajber prostora mogu da uvide koliko je moguće suočiti se sa klimatskim promenama. Sajber prostor može da služi kao tehnologija koja, preventivno, otkriva potencijalne uzroke klimatskih promena $\mathrm{i}$ da in na taj način preduhitri i da radi na njihovoj prevenciji (Allen, 2017). Mogućnost koju pruža sajber domen u borbi protiv klimatskih promena, treba da motiviše države širom sveta da naprave institucionalni okvir putem kojeg će se, udruženim snagama, boriti protiv klimatskih promena.

Jako je izazovno, u neku ruku apstraktno, povezivati klimatske promene i sajber bezbednost, međutim, klimatske promene na Arktiku mogu uticati na digitalnu infrastrukturu koja, na kraju, može uticati na fizičku infrastrukturu. Na primer, zdravstvena zaštita je digitalizovana i samim tim, klimatske promene na Arktiku zavise od sajber prostora i njenih instrumenata da pruži zdravstvene usluge i zaštite korisnicima. Takođe, klimatske promene na Arktiku mogu da poremete mrežu komunikacije, a samim tim, da poremete usluge zdravstvene zaštite, obrazovanja, osiguranja i slično. Istovremeno, digitalna infrastruktura se bavi snabdevanjem energije, klimatske promene na Arktiku mogu da poremete taj proces koji bi doveo do ljudskih žrtava (Klein, Hossain, 2020). Digitalizacija svih aspekata naših života, dovodi do činjenice da je sajber prostor jako važan faktor $u$ našim životima. Tačnije, sajber prostor sve više utiče na sve druge segmente naših života (Janković i dr, 2019). Klimatske promene sve više utiču na naš svakodnevni život u oblasti obrazovanja, ekonomije i slično. Klimatske promene na Arktiku mogu radikalno da utiču na svakodnevni život građana, odnosnu utiču na digitalni aspekt koji utiče na fizički aspekt. Stabilan i regulisan sajber prostor bi doveo do toga da postoji mehanizam koji omogućava ljudima pristup obrazovanju, finansijama, osiguranju i slično. Ovakva digitalna infrastruktura, dovodi do stabilnog okruženja koje se laške nosi sa izazovima klimatskih promena.

\section{REZULTATI I DISKUSIJA / RESULTS AND DUSCUSSION}

Sajber prostor i klimatske promene se, pre svega, analiziraju kao dva odvojena koncepta koji se po svojoj prirodi, u velikoj meri, razlikuju. Po svojoj prirodi, oni se razlikuju, ali po svome uticaju, treba 
ih posmatrati kao međusobno inkluzivne. Kao dva najvažnija faktora dvadeset i prvog veka, koji ne poznaju granice i, potencijalno, mogu da utiču na sve ljude ovog sveta, zaslužuju zajedničku analizu, zarad kreiranja zajedničkog obrasca i institucionalnog okvira. Antropogenost ova dva elemenata nas navodi, u poređenju sa drugim akademicima, da posmatramo ova dva elemenata kao jednu celinu jer, jedino, na taj način možemo da se nosimo sa izazovima. Ukoliko se povećanje nivoa mora prati kroz informacioni sistem, jako je važno da se postaramo da taj informacioni sistem ne bude predmet hakerskog napada, koji može da dovede do gubitka relevantnih informacija. Istovremeno, orijentacija istraživanja treba da uzme u obzir regulativnu agendu sajber prostora na međunarodnom nivou koja je prilično neuređena ili vrlo slabo uređena. Ukoliko države žele da se bore protiv klimatskih promena, neophodna je institucionalizacija i pravna regularnost sajber prostora na međunarodnom nivou. Države, pokušavaju da reše klimatske promene zajedničkim snagama na međunarodnom nivou, ali neće biti u mogućnosti da to urade efikasno, ukoliko nemaju pravni i institucionalni okvir za sajber odnose. Političari i akademici se fokusiraju na analizu međunarodnih odnosa u polju klimatskih promena, a ovaj rad pokušava da ukaže na to koliko je važna tehnička podrška koja dolazi iz regulacije sajber odnosa na međunarodnom nivou. Bez regulativnog okvira sajber prostora na međunarodnom nivou, ozbiljnija saradnja država i borba protiv klimatskih promena uz pomoć sajber domena je nemoguća. Autori koji analiziraju klimatske promene i sajber prostor, u velikoj meri, ne pridaju značaj digitalizaciji svega što nas okružuje. Ovo istraživanje, u velikoj meri, ukazuje na to da se sav naš život, a samim tim i svi relevantni podaci, digitalizuju i koliko je, upravo zbog toga, neraskidiva povezanost sajber prostora i klimatskih promena. Klimatske promene utiču i na nacionalnu bezbednosti i na ekonomiju države i iz tog razloga, istraživanje ukazuje na neophodnost kreiranja regulativnog okvira koji će dovesti do sinhronizovane borbe protiv klimatskih promena uz pomoć sajber domena. Primer klimatskih promena na Arktiku je ukazao na to koliko klimatske promene, koje utiču na digitalnu infrastrukturu, samim tim, na kraju utiču i na fizičku infrastrukturu. $U$ budućnost, fizička infrastruktura i digitalna infrastruktura neće imate jasne razlike, odnosno granice između njih će biti sve manje uočljive. Iz toga razloga, imajući u vidu da će klimatske promene kvalitativno uticati na život ljudi, borba protiv klimatskih promena nije dovoljna samo na fizičkom nivou, već i na digitalnom. Cilj ove analize je ukazivanje na sve veću potrebu regulisanja sajber prostora i na državnom i na međunarodnom nivou, kako bi postojala sve veća spremnost za zajedničku borbu protiv klimatskih promena.

\section{ZAKLJUČAK / CONCLUSION}

Sajber prostor i klimatske promene predstavljaju najveće izazove dvadeset i prvog veka. Povećanje globalne temperature, kao posledice emisije štetnih gasova i kreiranje efekta staklene bašte ukazuje na to da će klimatske promene i posledice koje nose, biti izazov u ovom veku. Sajber prostor, sa druge strane, kroz digitalizaciju svega što nas okružuje, takođe ukazuje na relevantnost $u$ ovom periodu. Povezanost ova dva elemenata i važan obostrani uticaj karakteriše ovaj rad. Borba protiv klimatskih promena mora da bude zajednička borba svih država ove planete, jer klimatske promene utiču na sve ljude ovog sveta. S obzirom na sve veću digitalizaciju svih relevantnih podataka, uređen i pravno regulisan sajber prostor je imperativ za uspešniju i sinhronizovaniju borbu protiv klimatskih promena. Paradoksalno, klimatske promene, utiču, odnosno trebalo bi da utiču na države, svojim negativnim efektima, da zajedno regulišu sajber prostor i da sarađuju, kako bi se uspešnije borili protiv klimatskih promena. Uzajamna povezanost sajber prostora i klimatskih promena je kompleksna jer, i dalje, ne postoji svest o tome koliko je važno da države zajednički rade na tome da iskoriste potencijale sajber prostora, pre svega kao institucionalni okvir na međunarodnom nivou za borbu protiv klimatskih promena.

\section{LITERATURA / REFERENCES}

[1] Aizebeokhai, A. P. (2009). Global warming and climate change: Realities, uncertainties and measures. International Journal of Physical Science, 4(13), 868-879.

[2] Allen, D. (2014). The center for climate \& security. (Council on Strategic Risks) Retrieved November 23, 2020, from Climate Change and Cyber Threats: Acknowledging the Links:

https://climateandsecurity.org/2014/09/climate -change-and-cyber-threats-acknowledgingthe-links/

[3] Allen, D. (2017). TechTarget. (TechTarget) Retrieved December 1, 2020, from How climate change threats can inform cybersecurity strategies:

https://searchcompliance.techtarget.com/opini on/How-climate-change-threats-can-informcybersecurity-strategies 
[4] Arntz, P. (2020). Malwarebytes Labs. (Malwarebytes). Retrieved November 23, 2020, from https://blog.malwarebytes.com/awareness/202 0/03/the-effects-of-climate-change-oncybersecurity/

[5] Belić, D. (2006). Global warming and greenhouse gases. Facta universitatis - Series: Physics, Chemistry and Technology, 4(1), 45-55.

[6] Blagojević, M. (2009). Ugrožavanje bezbednosti kao posledica globalnog zagrevanja. NBP. Nauka, bezbednost, policija, 14(3), 39-51.

[7] Carr, M., \& Lesniewska, F. (2020). Internet of Things, cybersecurity and governing wicked problems: learning from climate change governance. International Relations, 34(3), 391412.

[8] Change, I. P. (2007). Climate Change 2007: The Physical Science Basis. Geneva: World Meteorological Organization.

[9] Cilluffo, F. J., \& Cardash, S. L. (2013). Cyber Domain Conflicts in the 21st Century. The Whitehead Journal of Diplomacy and International Relations, XIV(1), 41-47.

[10] Dqindia. (2020). Data Quest. (Tech4growth) Retrieved November 23, 2020, from Five similarities between climate change and cyber security: https://www.dqindia.com/fivesimilarities-climate-change-cyber-security/

[11] Gilli, A., \& Gilli, M. (2019). Why China Has Not Caught Up Yet. International Security, 43(3), 141-189.

[12] Gnjatović, M. (2018). Primena koncepta frejminga u sekuritizaciji sajber pretnji. Godišnjak Fakulteta Bezbednosti, 1(1), 153-168.

[13] Hossain, K. (2018). Human Security in Cyberspace and Climate Change: A reflection from the European High North. European Journal of Human Security, Iss .2, 55-74.

[14] Janković, M., Jovanović, L., Gajdobranski, A., \& Jović Bogdanović, A. (2019). Uloga digitalne ekonomije u zaštiti životne sredine i ekosistema od prirodnih katastrofa. Ecologica, 94(1), 153158.

[15] Jonev, K. (2016). Sajber terorizam i upotreba sajber prostora u terorističke svrhe. Bezbednost, 58(2), 206-222.

[16] King, A. D., \& Harrington, L. J. (2018). The Inequality of Climate Change From 1.5 to $2^{\circ} \mathrm{C}$ of Global Warming. Geophysical Research Letters, 15(10), 5030-5033.

[17] Klein, J., \& Hossain, K. (2020). Conceptualising Human-centric Cyber Security in the Arctic in Light of Digitalisation and Climate Change. Artic Review on Law and Politics, 11, 1-18.

[18] Lawson, S. (2013). Beyond Cyber-Doom: Assessing the Limits of Hypothetical Scenarios in the Framing of Cyber-Threats. Journal of Information Technology \& Politics, 10(1), 86-103.

[19] Maness, R. C., \& Valeriano, B. (2015). The Impact of Cyber Conflict on International Interactions. Armed Forces \& Society, 42(2), 1-23.

[20] Miladinović-Bogavac, Ž. (2017). Poslovne prevare u sajber prostoru. Ekonomika, 63(4), 97-104.

[21] N2 Concultants. (2015). The Link: CyberSpace and The Climate: Our False Sense of Security Climate Change and Cyberthreats. McKinney: N2 Consultants, LLC.

[22] National Geographic. (2020). Environment (National Geographic) Retrieved November 17, 2020, from Global warming effects: https://www.nationalgeographic.com/environm ent/global-warming/global-warming-effects/

[23] Nešković, S. (2011). Ekonomska špijunaža u savremenoj međunarodnoj konstelaciji. Ekonomija: teorija i praksa, 4(1), 111-127.

[24] Ngongeh, L. A., Idika, K., \& Shehu, R. I. (2014). Climate Change/Global Warming and Its Impacts on Parasitology/ Entomology. The Open Parasitology Journal, 5(1), 1-11.

[25] Nye, J. (2010). Cyber Power. Cambridge: Harvard Kennedy School; Belfer Center for Science and International Affairs.

[26] Program Ujedinjenih nacija za razvoj. (2020). Blog. Retrieved from COVID-19 pandemija: Kriza ljudskog razvoja:

https://www.rs.undp.org/content/serbia/sr/hom e/blog/2020/the-covid-19-pandemic--ahuman-development-crisis.html

[27] Radić, V., Radić, N., \& Ravić, N. (2020). Uticaj pandemije korona virusa na ciljeve održivog razvoja i ekonomiju. Ecologica, 99(1), 366-375.

[28] Rathmell, A. (2008). Cyber-terrorism: The shape of future conflict? The RUSI Journal, 142(5), 40-45.

[29] Rid, T., \& Buchanan, B. (2014). Attributing Cyber Attacks. Journal of Strategic Studies, 38(1-2), 4-37.

[30] Saldinger, A. (2018, Januar 18). Devex. (Devex) Retrieved December 1, 2020, from https://www.devex.com/news/climatecybersecurity-top-list-of-global-threats-in-newreport-91899

[31] Seemma, P., Nandhini, S., \& Sowmiya, M. (2018). Overview of Cyber Security. Internati- 
onal Journal of Advanced Research in Computer and Communication Engineering, 7(11), 125-128.

[32] Slavković, R., \& Kršljanin, D. (2015). Uticaj operativnog okruženja na sajber pretnje. Vojno delo, 67(5), 333-356.

[33] Ujedinjene Nacije Srbija. (2020). COVID 19: Plan socio-ekonomskog odgovora. Retrieved from

https://serbia.un.org/sites/default/files/202012/serp-izvestaj-srp-web-30-11_1.pdf

[34] Vassileva, A., Simić, M., \& Stevanović, M. (2020). Implications of COVID-19 for international business. Ecologica, 100(1), 589-596.
[35] Vuletić, D. (2017). Upotreba sajber prostora u kontekstu hibridnog ratovanja. Vojno delo, 7(1), 308-325.

[36] Weart, S. R. (2008). The Discovery of Global Warming. Massachusetts: Harvard University Press.

[37] World Health Organization. (2019). Diseases. Retrieved from Coronavirus disease (COVID19) pandemic:

https://www.who.int/emergencies/diseases/no vel-coronavirus-

2019? gclid=Cj0KCQiA34OBBhCcARIsAG32u vNoLfpjwhvP5 iaRFOwu84M6krn5sGfibzGL5 AZ_HelVx94jJXVhacaAi4XEALw_wcB. 